\title{
Cu-MWCNT Composite Films Fabricated by Electrodeposition
}

\author{
Susumu Arai, ${ }^{a, *, z}$ Takashi Saito, ${ }^{a}$ and Morinobu Endo ${ }^{b}$ \\ ${ }^{a}$ Department of Chemistry and Material Engineering and ${ }^{b}$ Department of Electrical and Electronic
}

Engineering, Faculty of Engineering, Shinshu University, Nagano 380-8553, Japan

\begin{abstract}
Copper-multiwalled carbon nanotube (MWCNT) composite plating using a sulfuric base bath was studied. A dispersing agent was used to disperse the MWCNTs into the plating bath. The effects of electrodeposition conditions on the surface morphology, microstructure, and MWCNT content in the composite films were examined. The internal stress, hardness, electrical conductivity, and thermal conductivity of the composite films were also investigated. The current density remarkably affected the surface morphologies of the films, and a relatively smooth surface was obtained at lower current densities. The bath temperature affected the microstructure of the composite films; a compact microstructure was formed at a lower temperature. The MWCNT content in the composite film increased with increasing MWCNT concentration in the plating bath, reaching a maximum value of 0.55 mass $\%$. However, MWCNTs in the composite films tended to agglomerate for high MWCNT concentrations in the plating bath. An internal tensile stress was induced in the films. The hardness of the films was around $150 \mathrm{HV}$, and the electrical resistivity was approximately 2-2.5 $\mu \Omega \mathrm{cm}$. The thermal conductivity of the $\mathrm{Cu}-0.42$ mass \% MWCNT composite film was $355 \mathrm{~W} \mathrm{~m}^{-1} \mathrm{~K}^{-1}$. (C) 2010 The Electrochemical Society. [DOI: 10.1149/1.3280034] All rights reserved.
\end{abstract}

Manuscript submitted July 27, 2009; revised manuscript received November 2, 2009. Published January 12, 2010.

Carbon nanotubes $(\mathrm{CNTs})^{1,2}$ have excellent mechanical characteristics such as high tensile strength and elastic modulus. They also show high thermal and electrical conductivity values. Research into practical applications of CNTs, such as the preparation of resinCNT, ceramic-CNT, and metal-CNT composites, has therefore been actively pursued.

Recently, the fabrication of metal-CNT composites has been attempted using plating techniques. The tribological behavior of $\mathrm{Ni}-$ multiwalled carbon nanotube (Ni-MWCNT) composite coatings $\mathrm{s}^{3,4}$ was studied after deposition using an electroless plating technique. $\mathrm{Ni}-\mathrm{Co}-\mathrm{CNT}$ composite coatings ${ }^{3}$ fabricated by electrodeposition have also been reported. In addition, Chen et al. investigated the corrosion behavior of Ni-CNT composite coatings. ${ }^{6}$

The present authors, as well as others, have reported the fabrication of $\mathrm{Cu}-\mathrm{CNT}^{7-9}$ and Ni-CNT ${ }^{10-12}$ composite films using an electrodeposition technique, and the properties of these films have been investigated. We also reported that copper-multiwalled carbon nanotube $(\mathrm{Cu}-\mathrm{MWCNT})$ composite powder materials with a "sea urchin" shape ${ }^{13}$ and Ni-MWCNT composite powder materials with a "skewered dumpling" shape ${ }^{14}$ were formed using the electrodeposition technique. To extend practical applications of the CNT composite plating technology, control of the surface morphology and the microstructure of the composite films are very important. In addition, characterization of the physical properties of the films is essential. However, thus far, very few studies on the inter-relationships between electrodeposition conditions, microstructure, and physical properties of CNT composite films have been reported.

In the present study, we examined the effects of electrodeposition conditions on the surface morphology and microstructure of $\mathrm{Cu}-$ MWCNT composite plating films produced using a sulfuric bath. Furthermore, physical properties, such as hardness and electrical conductivity, of the composite films were characterized.

\section{Experimental}

The CNTs used in the present study were commercially available vapor-grown MWCNTs (Showa Denko Co., Ltd.), formed via catalyst-assisted chemical vapor deposition ${ }^{15}$ and heat-treated at $2800^{\circ} \mathrm{C}$ in an argon gas atmosphere for $30 \mathrm{~min}$. The MWCNTs were typically of $150 \mathrm{~nm}$ diameter and $15 \mu \mathrm{m}$ length. A sulfuric copper plating bath $\left(0.85 \mathrm{~mol} \mathrm{dm}{ }^{-3} \mathrm{CuSO}_{4} \cdot 5 \mathrm{H}_{2} \mathrm{O}+0.55 \mathrm{~mol} \mathrm{dm}\right.$ $\mathrm{H}_{2} \mathrm{SO}_{4}$ ) was used as the base bath. The MWCNTs did not disperse uniformly in the base bath; therefore, homogeneous dispersion of MWCNTs was achieved by the addition of a poly(acrylic acid) (PA5000 , mean molecular weight of 5000) dispersant ${ }^{7-14}$ to the base

* Electrochemical Society Active Member.

${ }^{\mathrm{z}}$ E-mail: araisun@ shinshu-u.ac.jp bath with stirring. The composition of the $\mathrm{Cu}-\mathrm{MWCNT}$ composite plating bath used in the present study was $0.85 \mathrm{~mol} \mathrm{dm}^{-3} \mathrm{CuSO}_{4} \cdot 5 \mathrm{H}_{2} \mathrm{O}+0.55 \mathrm{~mol} \mathrm{dm}^{-3} \mathrm{H}_{2} \mathrm{SO}_{4}+2$

$\times 10^{-5} \mathrm{~mol} \mathrm{dm}^{-3} \mathrm{PA}-5000+x \mathrm{~g} \mathrm{dm}^{-3}$ MWCNTs. A commercially available electrolytic cell (Microcell model I, Yamamoto-Ms Co., Ltd.) with internal dimensions of $65 \times 65 \times 95 \mathrm{~mm}$ was employed for the electrodeposition. The volume of the plating bath was $250 \mathrm{~cm}^{3}$. A pure copper plate with an exposed surface area of $10 \mathrm{~cm}^{2}(3 \times 3.33 \mathrm{~cm})$ was mainly used as the substrate. A copper plate containing a small amount of phosphorus was used as the anode. Electrodeposition was performed at various current densities, bath temperatures, and MWCNT concentrations in the plating baths with aeration. The microcell used has holes at the bottom for aeration. The aeration was carried out using an air pump (hull cell air pump, Yamamoto-Ms Co., Ltd.) exclusively for this purpose.

The surface morphology and microstructure of the $\mathrm{Cu}-\mathrm{MWCNT}$ composite films were examined using a field-emission scanning electron microscope (SEM, JEOL JSM-7000F). An exclusive sample preparation equipment (cross-section polisher, JEOL SM09010) was used to prepare cross-sectional samples for observations. Cathode polarization curves were measured using an electrochemical measurement system (Hokuto Denko HZ-5000). A pure copper plate, a copper plate containing a small amount of phosphorus, and a saturated calomel electrode were used as the working electrode, counter electrode, and reference electrode, respectively. Measurements were carried out with aeration using the same electrolytic cell mentioned above. The MWCNT content in the composite films was determined by direct weighing. For the weight measurements, thick $\mathrm{Cu}-\mathrm{MWCNT}$ composite films (over $8 \mathrm{~g}$ ) were electrodeposited. Subsequently, the copper matrix of the films was dissolved in nitric acid. The MWCNTs in the nitric acid solution were then filtered, dried, and weighed. Internal stress was measured using a stress analyzer (specialty testing and development 683EC analyzer). The quantity of electricity in the electrodeposits for the internal stress measurements was $60 \mathrm{C} \mathrm{cm}^{-2}$. Hardness testing of the deposited films was performed using a micro-Vickers hardness tester (Shimadzu Seisakusho Co.). The electrical resistivity of the composite films was investigated by a four-terminal method (a fourpoint probe system) after the removal of the stainless steel substrate. Thermal conductivity was measured by a laser flash method (ULVAC RIKO laser flash PC-7000) at room temperature. For this measurement, thick films were electrodeposited on a stainless steel substrate, then removed from the substrate, and finally formed into disks with $10 \mathrm{~mm}$ diameter and $2 \mathrm{~mm}$ thickness.

\section{Results and Discussion}

Figure 1 shows surface SEM images of the composite films electrodeposited at various current densities. The bath temperature was 

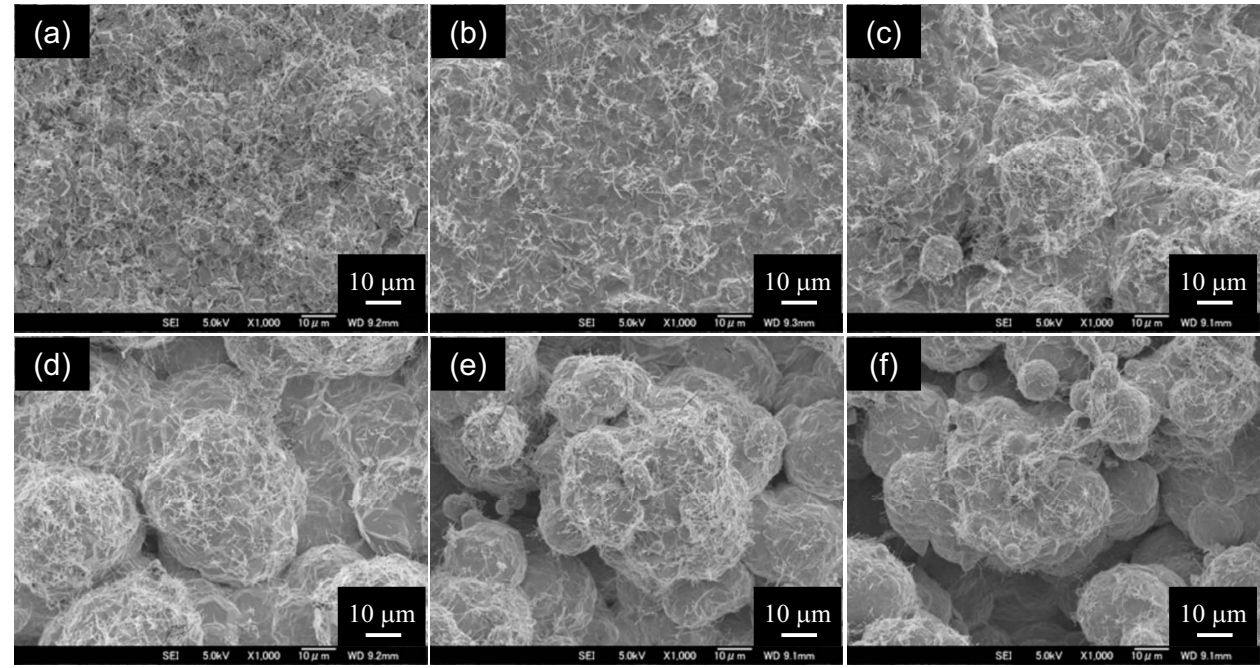

Figure 1. Surface SEM images of $\mathrm{Cu}-$ MWCNT composite films electrodeposited at current densities of (a) 0.5 , (b) 1 , (c) 2 , (d) 3 , (e) 4, and (f) $5 \mathrm{~A} \mathrm{dm}^{-2}$. MWCNT concentration in the plating bath: $2 \mathrm{~g} \mathrm{dm}^{-3}$. Bath temperature: $25^{\circ} \mathrm{C}$. $25^{\circ} \mathrm{C}$, and the MWCNT concentration in the composite plating bath was $2 \mathrm{~g} \mathrm{dm}^{-3}$. The total electricity was $150 \mathrm{C} \mathrm{cm}^{-2}$. Surface roughness remarkably increased with increasing current density, and a very bumpy morphology was observed at $5 \mathrm{~A} \mathrm{dm}^{-2}$. A relatively smooth surface morphology was obtained below $1 \mathrm{~A} \mathrm{dm}^{-2}$. Enlarged images of Fig. 1 are shown in Fig. 2. MWCNTs were incorporated into the copper matrix for all current densities. In particular, a smooth and compact surface morphology was obtained at $1 \mathrm{~A} \mathrm{dm}^{-2}$. Spherical copper deposits incorporating MWCNTs were typically formed at $5 \mathrm{~A} \mathrm{dm}^{-2}$. This result agrees with the results of our previous work. ${ }^{13}$ Figure 3 shows cross-sectional SEM images of the composite films shown in Fig. 1. It is evident that the surface roughness of the films tends to increase with increasing current density, corresponding to the images in Fig. 1. Enlarged images of Fig. 3 are shown in Fig. 4. The dark regions are cross sections of the MWCNTs. The MWCNTs were homogeneously distributed in the composite films without cohesion, and major defects such as voids and gaps between the copper matrix and MWCNTs were not observed at any current density.

Figure 5 shows schematic illustrations of the growth processes of the Cu-MWCNT composite films at different current densities. When the current density is relatively low, below $1 \mathrm{~A} \mathrm{dm}^{-2}$ in the present study, copper electrodeposits on the substrate, trapping and embedding MWCNTs in the depositing copper matrix, resulting in a relatively smooth surface morphology (Fig. 5a). However, in a higher current density, above $2 \mathrm{~A} \mathrm{dm}^{-2}$ in the present study, the
MWCNTs are at first incorporated into the deposited copper matrix. Next, copper electrodeposits not only on the existing copper matrix but also on the protruding tips of the MWCNTs incorporated into the deposited copper matrix. Newly arriving MWCNTs are then incorporated into the latter copper regions, ${ }^{8,14}$ resulting in a bumpy surface morphology (Fig. 5b). MWCNTs, especially graphitized MWCNTs, have relatively high electrical conductivity in the axial direction due to their structure (the highly preferred orientation of their graphitic basal planes is parallel to the MWCNT axis with an annular ring texture in the cross section). ${ }^{16}$ Therefore, if the MWCNTs are incorporated in the deposited copper matrix, copper may electrodeposit on the protruding tips of the MWCNTs, as shown in Fig. 5b. If defects, such as vacancies, exist on the outer surface of the MWCNTs, copper might also be electrodeposited in these regions. ${ }^{14}$ However, we assume that no defects exist on the outer surface of the MWCNTs in this study.

Figure 6 shows schematic illustrations of the electrodeposition behavior of copper on the deposited $\mathrm{Cu}-\mathrm{MWCNT}$ composite film. When the applied current density is relatively low, below $1 \mathrm{~A} \mathrm{dm}^{-2}$ in the present study, the corresponding cathode overpotential $\left(\eta_{\text {low }}\right)$ may be small and the potential of a protruding tip of the MWCNT $\left(E_{\mathrm{CNT}-\mathrm{low}}\right)$ may not be more negative than the electrodeposition potential of copper on the protruding tip of the MWCNT $\left(E_{\text {depo }}\right)$. It is considered that the overpotential needed for copper deposition on the protruding tip of the MWCNT $\left(\eta_{\text {tip-depo }}\right)$ is higher than that on
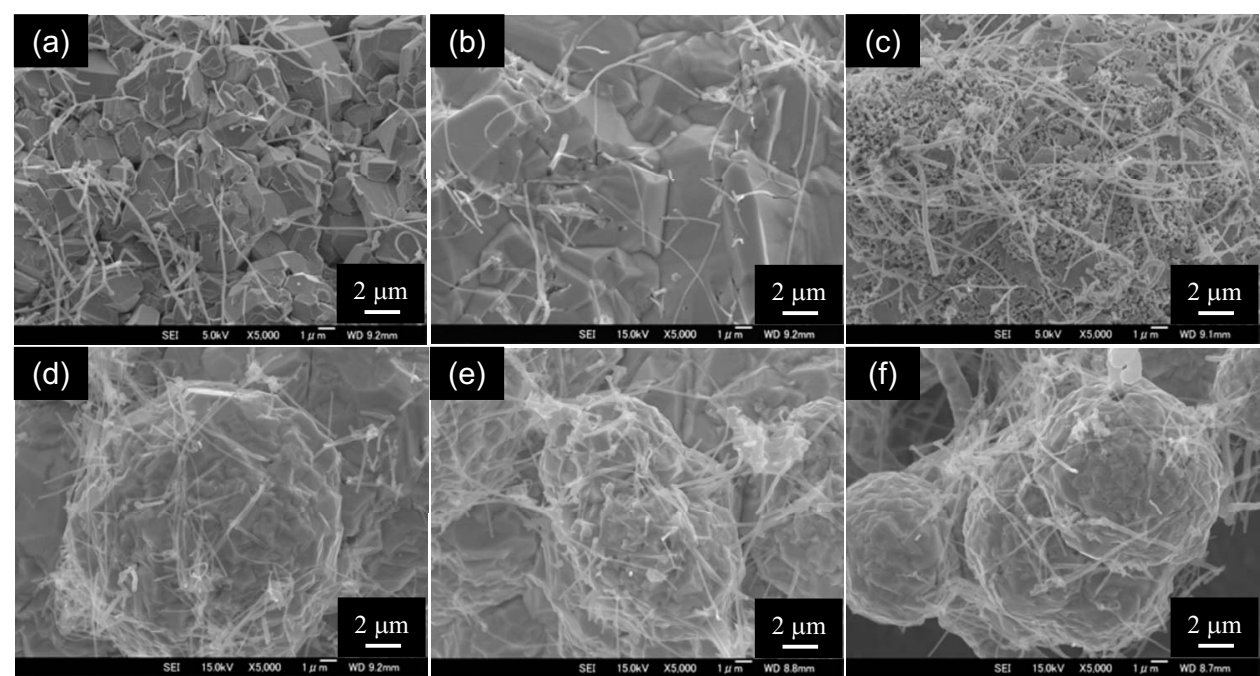

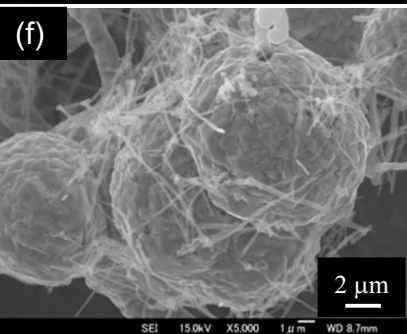

Figure 2. Enlarged images of Fig. 1: (a) 0.5 , (b) 1 , (c) 2 , (d) 3 , (e) 4, and (f) $5 \mathrm{~A} \mathrm{dm}^{-2}$. MWCNT concentration in the plating bath: $2 \mathrm{~g} \mathrm{dm}^{-3}$. Bath temperature: $25^{\circ} \mathrm{C}$. 

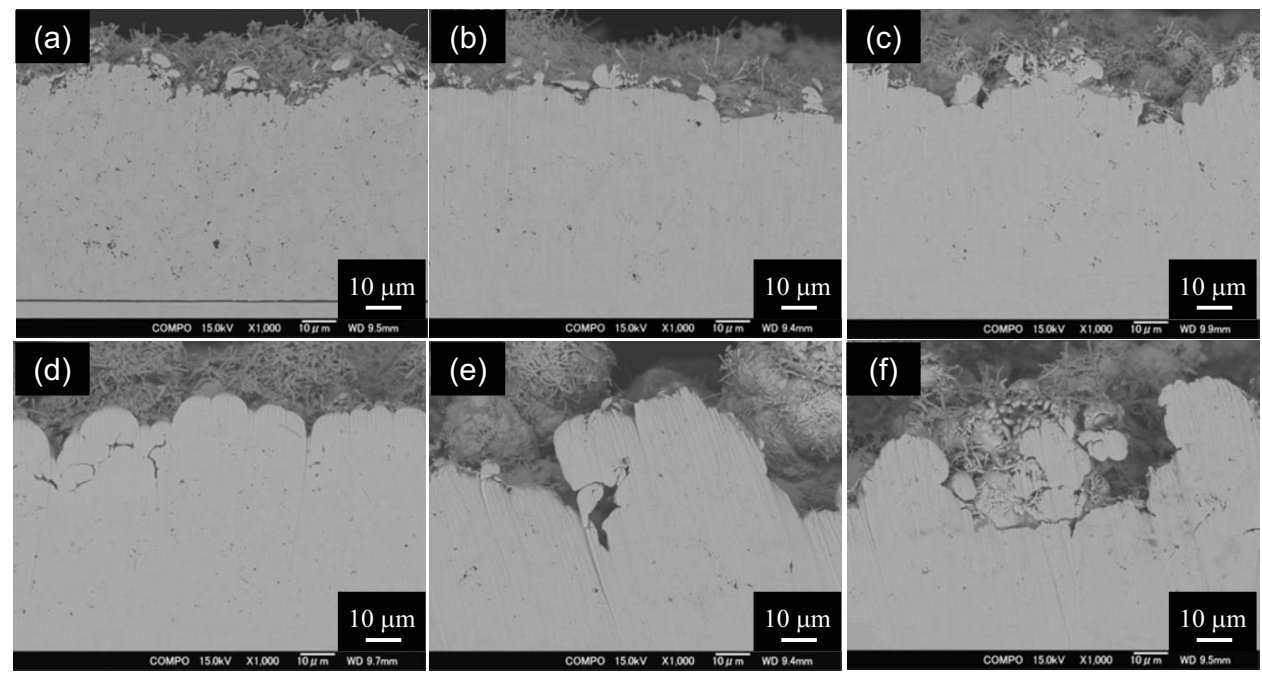

Figure 3. Cross-sectional SEM images of $\mathrm{Cu}-\mathrm{MWCNT}$ composite films electrodeposited at various current densities: (a) 0.5 , (b) 1 , (c) 2, (d) 3, (e) 4, and (f) $5 \mathrm{~A} \mathrm{dm}^{-2}$. MWCNT concentration in the plating bath: $2 \mathrm{~g} \mathrm{dm}^{-3}$. Bath temperature: $25^{\circ} \mathrm{C}$

the deposited copper surface, which is $\eta_{\text {low }}$. This resulted in copper deposition only on the deposited copper surface at a low current density (Fig. 6a). However, when the applied current density is relatively high, above $2 \mathrm{~A} \mathrm{dm}^{-2}$ in the present study, the corresponding cathode overpotential $\left(\eta_{\text {high }}\right)$ may be large and the potential of a protruding tip of the MWCNT ( $\left.E_{\mathrm{CNT} \text {-high }}\right)$ may be more negative than $E_{\text {depo }}$; that is, $\eta_{\text {high }}$ may be higher than $\eta_{\text {tip-depo }}$, resulting in copper deposition both on the deposited copper surface and the protruding tip of the single MWCNT (Fig. 6b). The cathode overpotential consists of a charge-transfer overpotential, a diffusion overpotential, a reaction overpotential, and a crystallization overpotential. ${ }^{17}$ We examine the effect of each of these overpotentials in a future

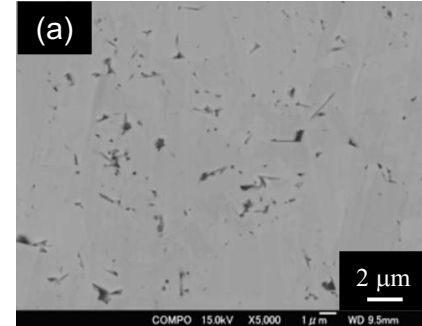

\section{(d)}

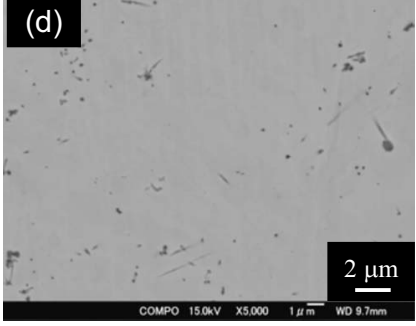

\section{(b)}

(e)
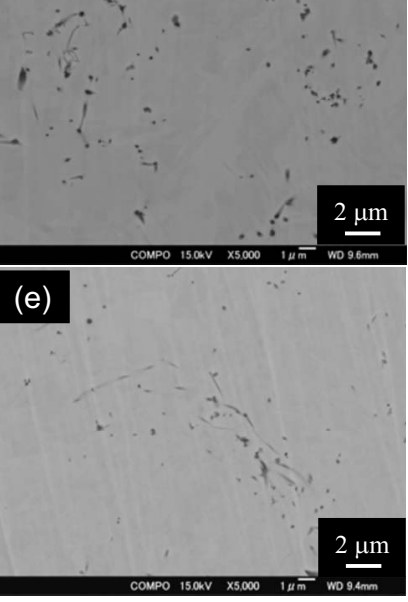

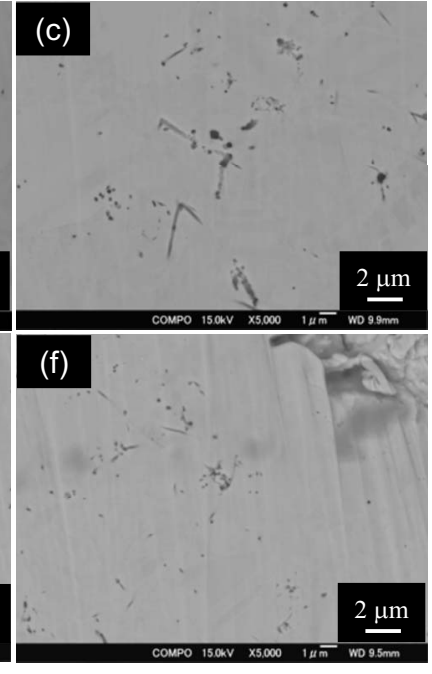

(c)

Smooth surface

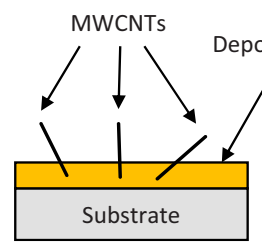

Deposited copper

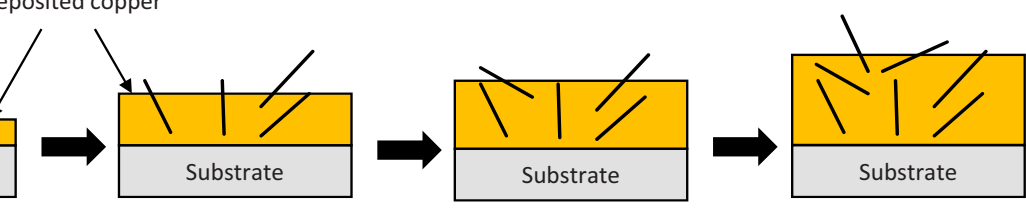

(a)

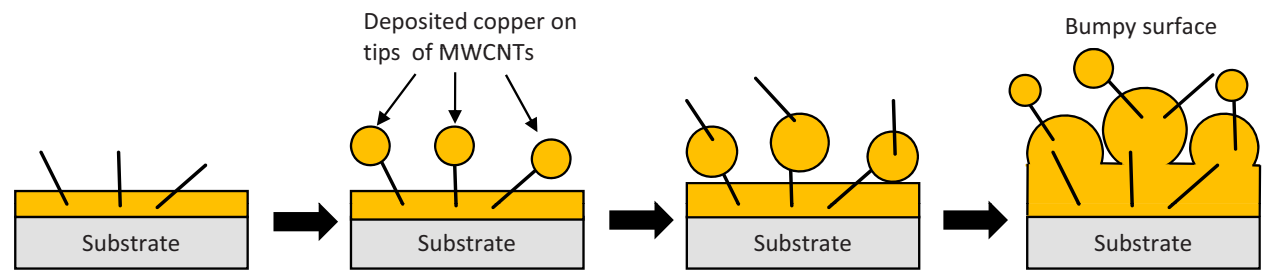

Figure 4. Enlarged images of Fig. 3: (a) 0.5 , (b) 1 , (c) 2, (d) 3, (e) 4, and (f) $5 \mathrm{~A} \mathrm{dm}^{-2}$. MWCNT concentration in the plating bath: $2 \mathrm{~g} \mathrm{dm}^{-3}$. Bath temperature: $25^{\circ} \mathrm{C}$.

(b)

Figure 5. (Color online) Schematic illustrations for growth processes of the $\mathrm{Cu}-$ MWCNT composite films (a) at low current density $\left(\leq 1 \mathrm{~A} \mathrm{dm}^{-2}\right)$ and (b) at high current density $\left(\geq 2 \mathrm{~A} \mathrm{dm}^{-2}\right)$. 


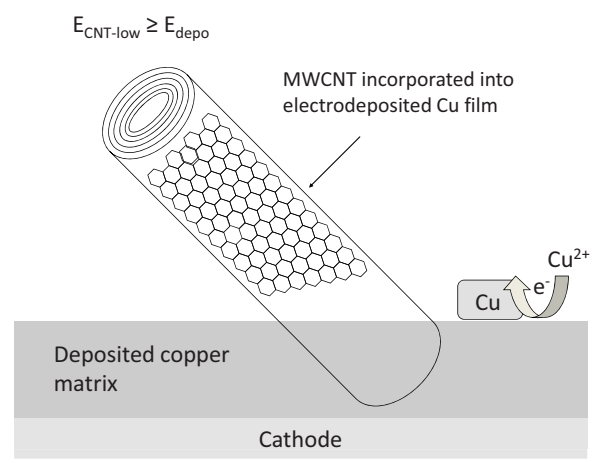

(a)

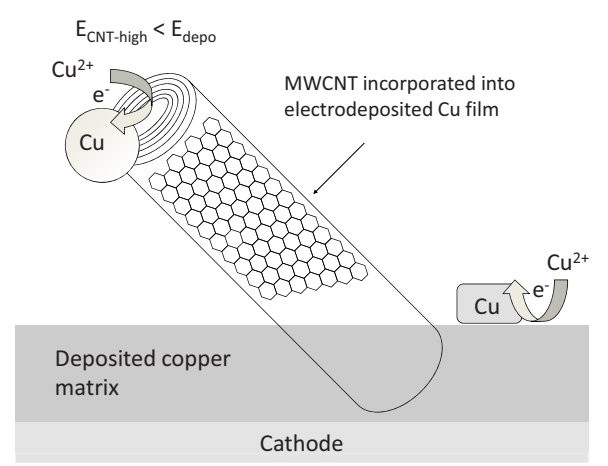

(b)
Figure 6. (Color online) Schematic illustration of copper deposition behavior on the tip of a MWCNT: (a) At low current density ( $\left.\leq 1 \mathrm{~A} \mathrm{dm}^{-2}\right)$ and (b) at high current density $\left(\geq 2 \mathrm{~A} \mathrm{dm}^{-2}\right)$. $E_{\text {depo, the }}$ electrodeposition potential of copper on a protruding tip of the MWCNT; $E_{\mathrm{CNT} \text {-low, }}$ the potential of a protruding tip of the MWCNT at low current density; $E_{\mathrm{CNT} \text {-high }}$, the potential of a protruding tip of the MWCNT at high current density. work. Figure 7 shows cathode polarization curves for various baths. Measurements were carried out at $25^{\circ} \mathrm{C}$. Curve (a) indicates the electrodeposition behavior of copper from the base bath. Curve (b)

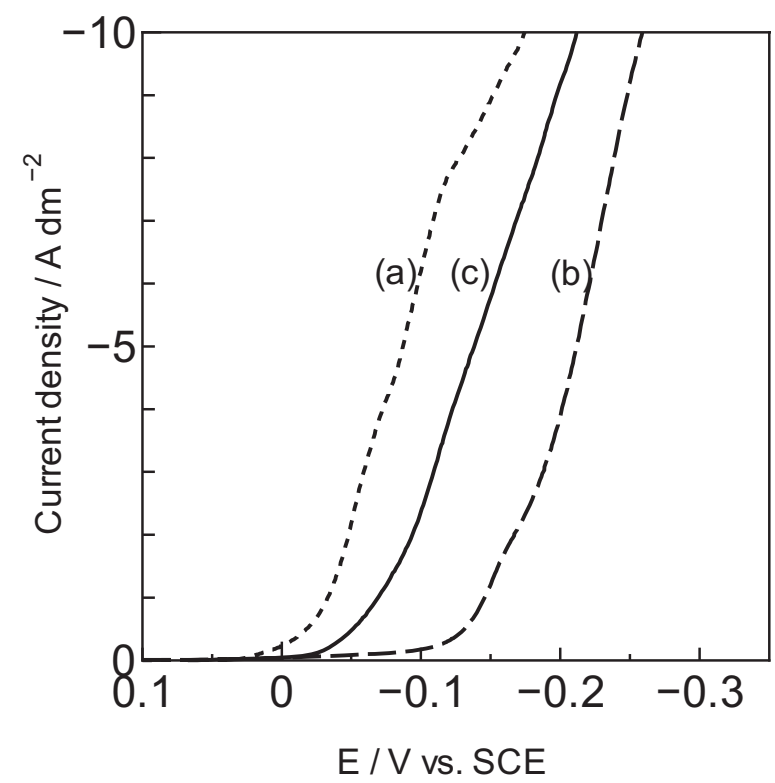

Figure 7. Cathode polarization curves for various plating baths. (a) Base bath $\left(0.85 \mathrm{M} \mathrm{CuSO}_{4} \cdot 5 \mathrm{H}_{2} \mathrm{O}+0.55 \mathrm{M} \mathrm{H}_{2} \mathrm{SO}_{4}\right)$, (b) base bath +2 $\times 10^{-5} \mathrm{~mol} \mathrm{dm}^{-3} \mathrm{PA}-5000$, and (c) composite plating bath [(b) $+2 \mathrm{~g} \mathrm{dm}^{-3} \mathrm{MWCNTs}$. Agitation: Aeration. Bath temperature: $25^{\circ} \mathrm{C}$. indicates the electrodeposition behavior of copper from the base bath $+2 \times 10^{-5} \mathrm{~mol} \mathrm{dm}{ }^{-3}$ PA-5000. Electrodeposition of copper was evidently inhibited by the addition of PA-5000. It is thought that PA-5000 was adsorbed on the depositing copper surface, which inhibited further electrodeposition of copper. Curve (c) in Fig. 7 indicates the electrodeposition behavior of copper from a composite plating bath (base bath $+2 \times 10^{-5} \mathrm{~mol} \mathrm{dm}^{-3}$ PA-5000 $+2 \mathrm{~g} \mathrm{dm}^{-3}$ MWCNTs). The inhibition effect of copper deposition was reduced by the addition of MWCNTs compared to curve (b). As PA-5000 is a dispersing agent for MWCNTs and is adsorbed on the MWCNTs, the concentration of free PA-5000 in the bath decreased, resulting in a reduction in the inhibition effect of copper deposition. From curve (c), the cathode potentials corresponding to current densities of 1 and $5 \mathrm{~A} \mathrm{dm}^{-2}$ are -0.07 and $-0.14 \mathrm{~V}$, respectively. Thus, as explained above, in actuality, the cathode potential became more negative with increasing current density.

Figure 8 shows surface SEM images of $\mathrm{Cu}-\mathrm{MWCNT}$ composite films electrodeposited at various bath temperatures. The applied current density was $1 \mathrm{~A} \mathrm{dm}^{-2}$, and the MWCNT concentration in the plating bath was $2 \mathrm{~g} \mathrm{dm}^{-3}$. MWCNTs were incorporated in the films for all temperatures. However, cohesion of MWCNTs occurs at high temperatures. Also, the surface roughness of the $\mathrm{Cu}-$ MWCNT composite films increased with increasing temperature. Figure 9 shows cross-sectional SEM images of the $\mathrm{Cu}-\mathrm{MWCNT}$ composite films electrodeposited at various bath temperatures. While the microstructure of the film electrodeposited at $25^{\circ} \mathrm{C}$ was compact and had no defects such as voids or gaps, the microstructure of the films electrodeposited above $40^{\circ} \mathrm{C}$ was porous. It is thought that the effect of PA-5000, the dispersing agent for MWCNTs, changed at high temperatures. We plan to carry out a
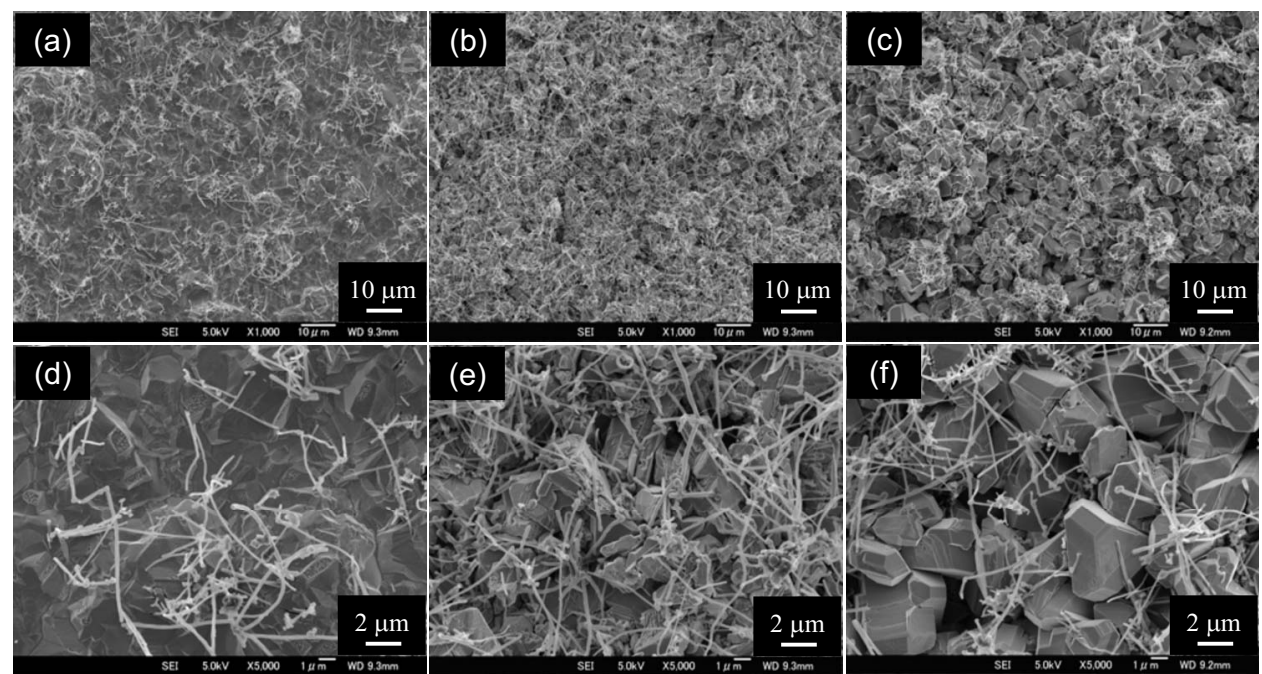

Figure 8. Surface SEM images of $\mathrm{Cu}-$ MWCNT composite films electrodeposited at various bath temperatures of (a) 25 , (b) 40 , and (c) $60^{\circ} \mathrm{C}$; (d)-(f) are enlarged images of (a)-(c), respectively. Current density: $1 \mathrm{~A} \mathrm{dm}^{-2}$. MWCNT concentration in the plating bath: $2 \mathrm{~g} \mathrm{dm}^{-3}$. 


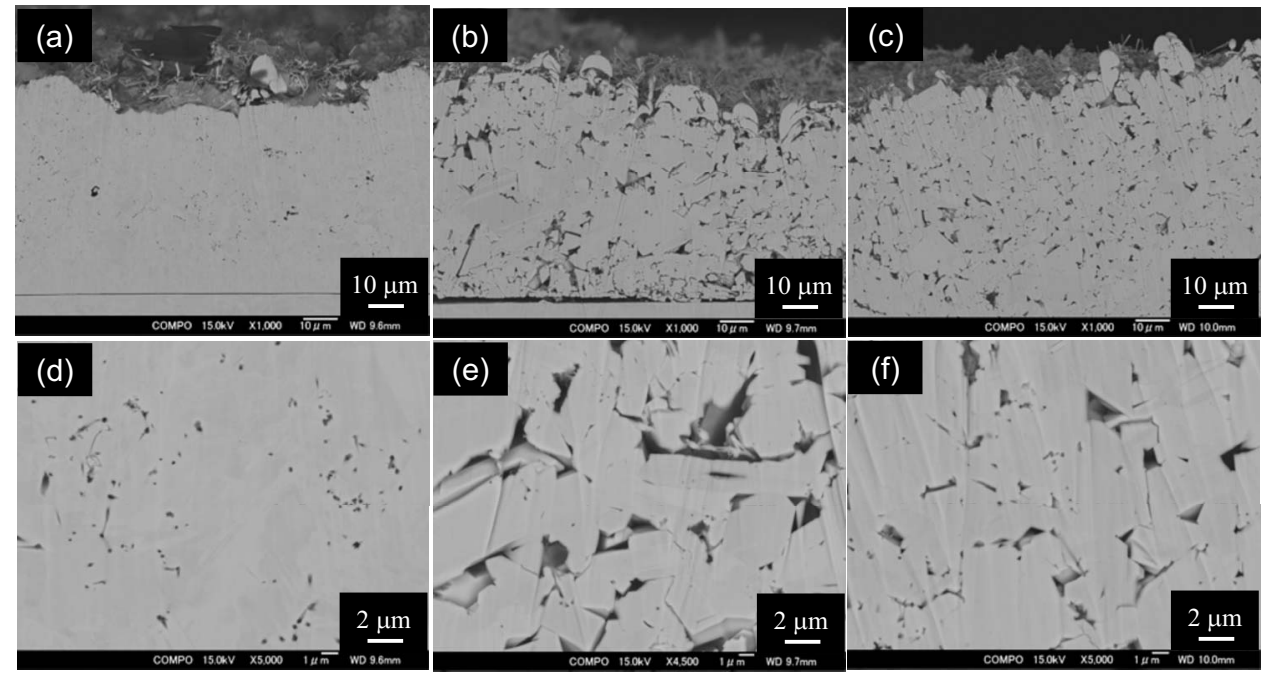

Figure 9. Cross-sectional SEM images of Cu-MWCNT composite films electrodeposited at various bath temperatures of (a) 25 , (b) 40 , and (c) $60^{\circ} \mathrm{C}$; (d)-(f) are enlarged images of (a)-(c), respectively. Current density: $1 \mathrm{~A} \mathrm{dm}^{-2}$. MWCNT concentration in the plating bath: $2 \mathrm{~g}$ $\mathrm{dm}^{-3}$.

detailed examination of the effects of temperature in a future work. In any case, because $\mathrm{Cu}-\mathrm{MWCNTs}$ with a porous microstructure cannot be expected to have good physical properties, such as high electrical conductivity, the temperature used in this study was fixed at $25^{\circ} \mathrm{C}$.

Figure 10 shows surface SEM images of the $\mathrm{Cu}-\mathrm{MWCNT}$ composite films electrodeposited under various MWCNT concentrations in the plating bath. The applied current density and bath temperature were $1 \mathrm{~A} \mathrm{dm}^{-2}$ and $25^{\circ} \mathrm{C}$, respectively. Although, MWCNTs were relatively homogeneously incorporated in the deposited copper films for all MWCNT concentrations, cohesion of MWCNTs was observed at high concentrations. Figure 11 shows cross-sectional SEM images of the $\mathrm{Cu}-\mathrm{MWCNT}$ composite films electrodeposited under various MWCNT concentrations in the plating bath. MWCNTs were homogeneously embedded in all the films, and no voids or gaps were seen in any of these films. However, cohesion of MWCNTs was found in the films formed at high MWCNT concentrations in the plating baths corresponding to Fig. 10. It is likely that the MWCNTs did not completely disperse in the plating bath at high MWCNT concentrations, resulting in cohesion. Such cohesion is not desirable for good physical properties such as high thermal conductivity.

Figure 12 shows the relationship between the MWCNT concentration in the plating baths and the MWCNT content in the composite plating films. The applied current density and bath temperature were $1 \mathrm{~A} \mathrm{dm}^{-2}$ and $25^{\circ} \mathrm{C}$, respectively. The MWCNT content in the films increased with increasing MWCNT concentration in the plating baths, reaching a maximum value of 0.55 mass $\%$. The mea-
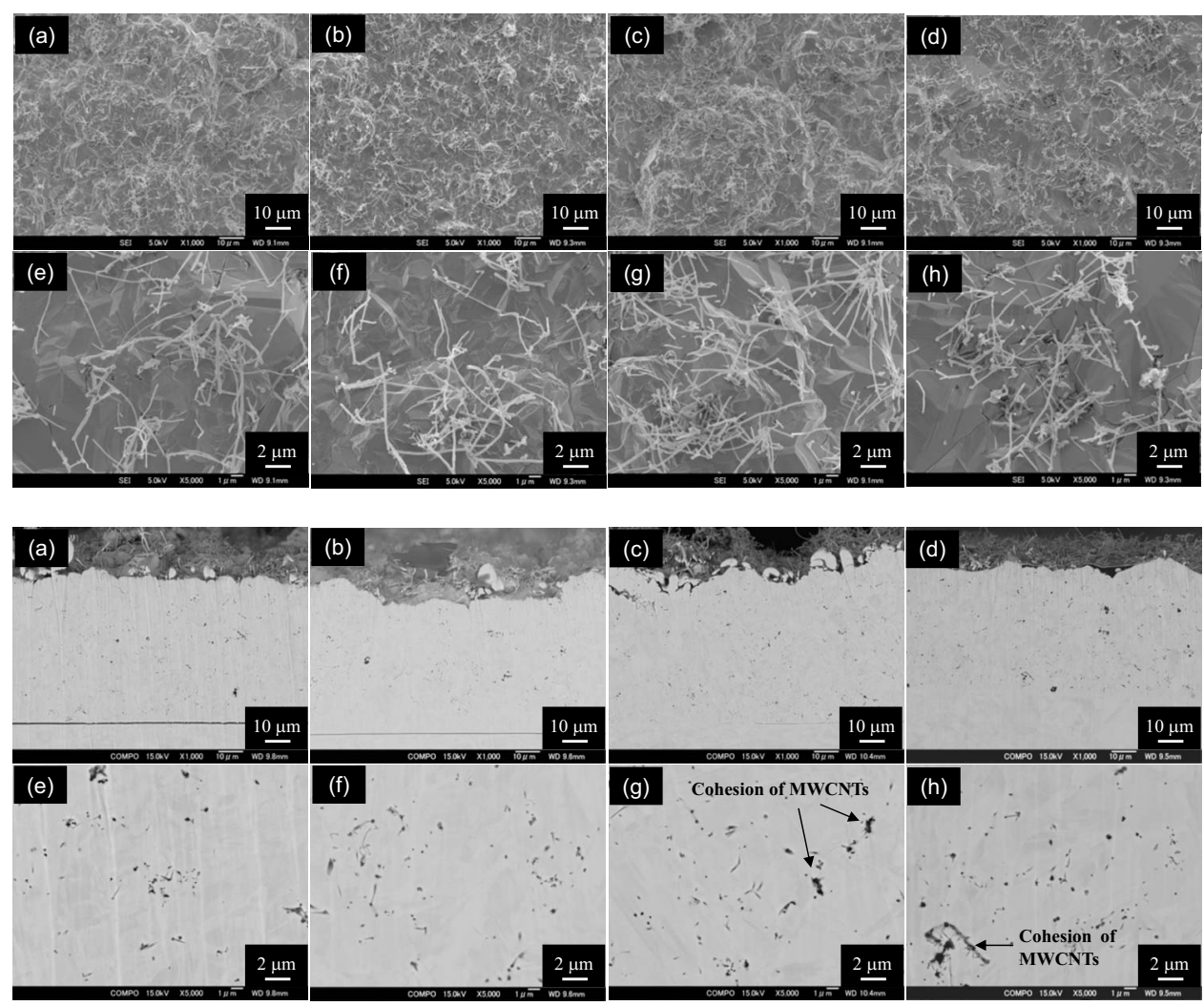

Figure 10. Surface SEM images of $\mathrm{Cu}-$ MWCNT composite films electrodeposited at various MWCNT concentrations in the plating baths of (a) 0.5, (b) 2, (c) 5, and (d) $10 \mathrm{~g} \mathrm{dm}^{-3}$; (e)-(h) are enlarged images of (a)-(d), respectively. Current density: $1 \mathrm{~A} \mathrm{dm}^{-2}$. Temperature: $25^{\circ} \mathrm{C}$.

Figure 11. Cross-sectional SEM images of $\mathrm{Cu}-\mathrm{MWCNT}$ composite films electrodeposited at various MWCNT concentrations in the baths of (a) 0.5 , (b) 2 , (c) 5 , and (d) $10 \mathrm{~g} \mathrm{dm}^{-3}$; (e)-(h) are enlarged images of (a)-(d), respectively. Current density: $1 \mathrm{~A} \mathrm{dm}{ }^{-2}$. Temperature: $25^{\circ} \mathrm{C}$. 


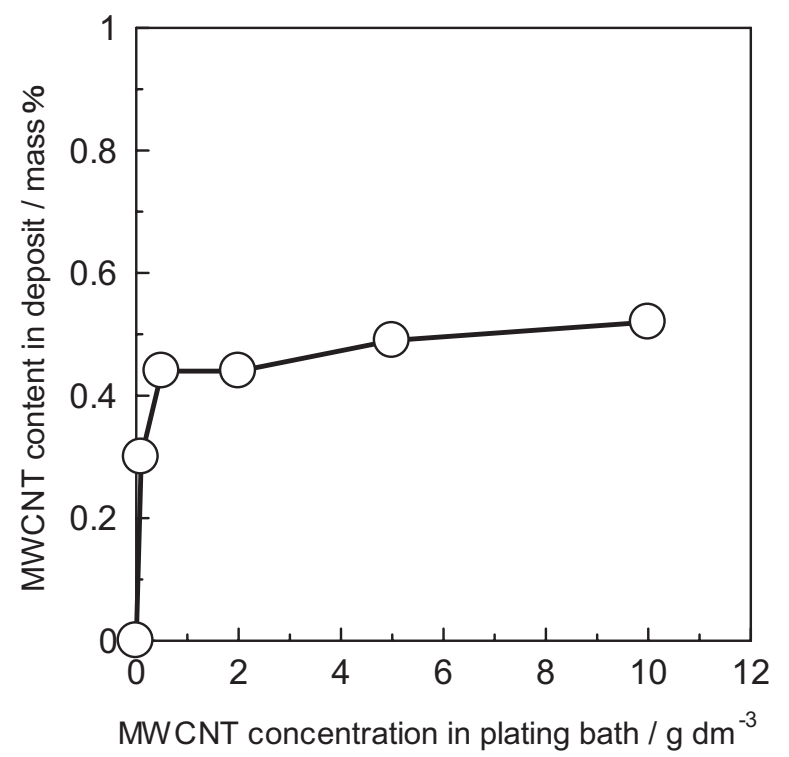

Figure 12. Relationship between MWCNT concentration in the bath and MWCNT content in the film. Current density: $1 \mathrm{~A} \mathrm{dm}^{-2}$. Temperature: $25^{\circ} \mathrm{C}$.

sured values of the MWCNT content in the composite films are consistent with the cross-sectional SEM images of the $\mathrm{Cu}-\mathrm{MWCNT}$ composite films (Fig. 11).

Figure 13 shows the relationship between the internal stress of the $\mathrm{Cu}-\mathrm{MWCNT}$ composite films, the MWCNT concentration in the plating baths, and the MWCNT content in the composite films. The applied current density and bath temperature were $1 \mathrm{~A} \mathrm{dm}^{-2}$ and $25^{\circ} \mathrm{C}$, respectively. The internal stress was tensile in all the films and decreased with increasing MWCNT content in the plating baths. Therefore, the MWCNT content in the composite films seems to affect the internal stress. However, because the internal stress of the film formed from the plating bath without MWCNTs (base bath $+2 \times 10^{-5} \mathrm{~mol} \mathrm{dm}^{-3}$ PA-5000) was $1.75 \mathrm{~kg} \mathrm{~mm}^{-2}$, which is much larger than that of a pure copper film $\left(0.65 \mathrm{~kg} \mathrm{~mm}^{-2}\right)$ formed from the base bath, it can be concluded that PA-5000 increased the tensile stress in the film. When the MWCNT concentration in the

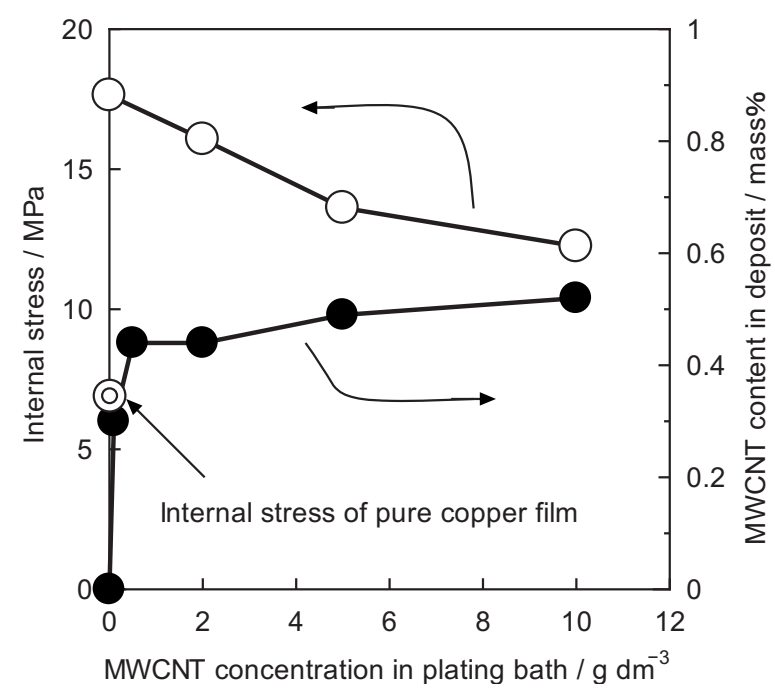

Figure 13. Relationship between MWCNT concentration in the plating bath, internal stress, and MWCNT content in the film. Current density: $1 \mathrm{~A} \mathrm{dm}^{-2}$. Temperature: $25^{\circ} \mathrm{C}$. The double circle symbol shows the internal stress value for the pure copper film electrodeposited from the base bath.

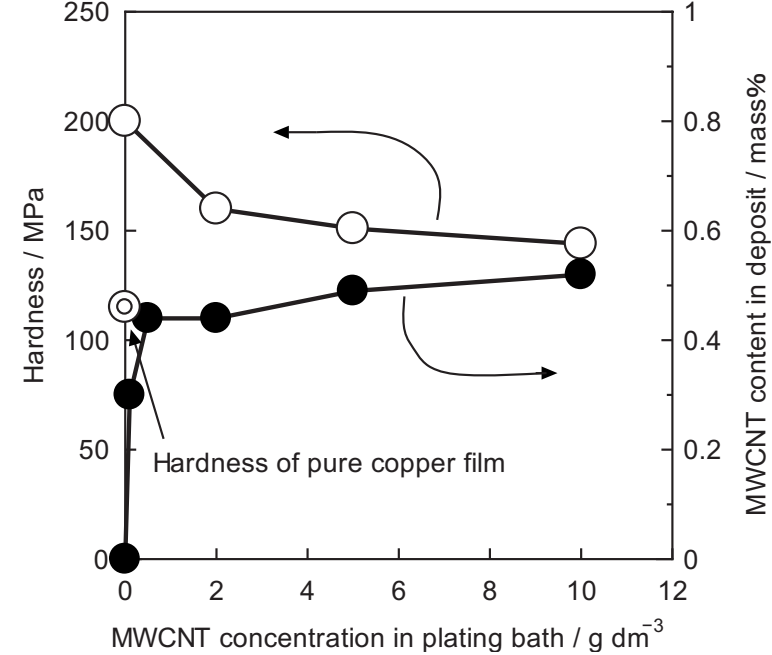

Figure 14. Relationship between MWCNT concentration in the plating bath, hardness, and MWCNT content in the film. Current density: $1 \mathrm{~A} \mathrm{dm}^{-2}$. Temperature: $25^{\circ} \mathrm{C}$. The double circle symbol shows the hardness of the pure copper film electrodeposited from the base bath.

plating bath was zero, $2 \times 10^{-5} \mathrm{~mol} \mathrm{dm}^{-3}$ PA-5000 affected the depositing film, resulting in a large internal stress. Because PA-5000 strongly inhibited copper deposition (Fig. 7b), it is thought that PA5000 was adsorbed on and incorporated into the film, resulting in an increase in internal stress. When MWCNTs were added to the plating bath, PA-5000 is thought to adsorb on the MWCNTs. As the concentration of free PA-5000 in the plating bath decreased with increasing MWCNT concentration in the plating baths, the decrease in internal stress may be mainly caused by the decreased free PA5000 concentration in the plating baths.

Figure 14 shows the relationship between the hardness of the $\mathrm{Cu}-\mathrm{MWCNT}$ composite films, the MWCNT concentration in the composite plating bath, and the MWCNT content in the composite films. The applied current density and bath temperature were $1 \mathrm{~A} \mathrm{dm}^{-2}$ and $25^{\circ} \mathrm{C}$, respectively. The hardness of the films decreased with increasing MWCNT content in the plating baths. A film with a maximum hardness value of $200 \mathrm{HV}$ was obtained from a bath without MWCNTs, that is, the base bath +2 $\times 10^{-5} \mathrm{~mol} \mathrm{dm}^{-3}$ PA-5000. The hardness of a pure copper film electrodeposited from the base bath was much lower at $111 \mathrm{HV}$. As mentioned above, free PA-5000 concentration decreases with increasing MWCNT concentration in the plating bath. Therefore, the decrease in hardness can be thought to be caused by a decrease in the free PA-5000 concentration in the plating bath. However, as the hardness of the composite film decreased with increasing MWCNT content in the composite films, it can be concluded that the effect of MWCNT dispersion hardening on the hardness of the composite film was small compared to the effect of PA-5000.

Figure 15 shows the relationship between the electrical resistivity of the films, the MWCNT concentration in the plating baths, and the MWCNT content in the films. The applied current density and bath temperature were $1 \mathrm{~A} \mathrm{dm}^{-2}$ and $25^{\circ} \mathrm{C}$, respectively. The electrical resistivity decreased with increasing MWCNT concentration in the plating baths, reaching a minimum value of $2.05 \mu \Omega \mathrm{cm}$. The electrical resistivity of a film formed from a bath without MWCNTs, that is, the base bath $+2 \times 10^{-5} \mathrm{~mol} \mathrm{dm}^{-3}$ PA-5000, was $2.75 \mu \Omega \mathrm{cm}$. Meanwhile, the electrical resistivity of a pure copper film formed from the base bath was $1.89 \mu \Omega \mathrm{cm}$. As the free PA5000 concentration decreased with increasing MWCNT concentration in the plating baths, the decrease in the electrical resistivity was apparently caused by a decrease in the free PA-5000 concentration in the plating bath. However, the electrical resistivity seems to decrease with increasing MWCNT content in the films. However, as 


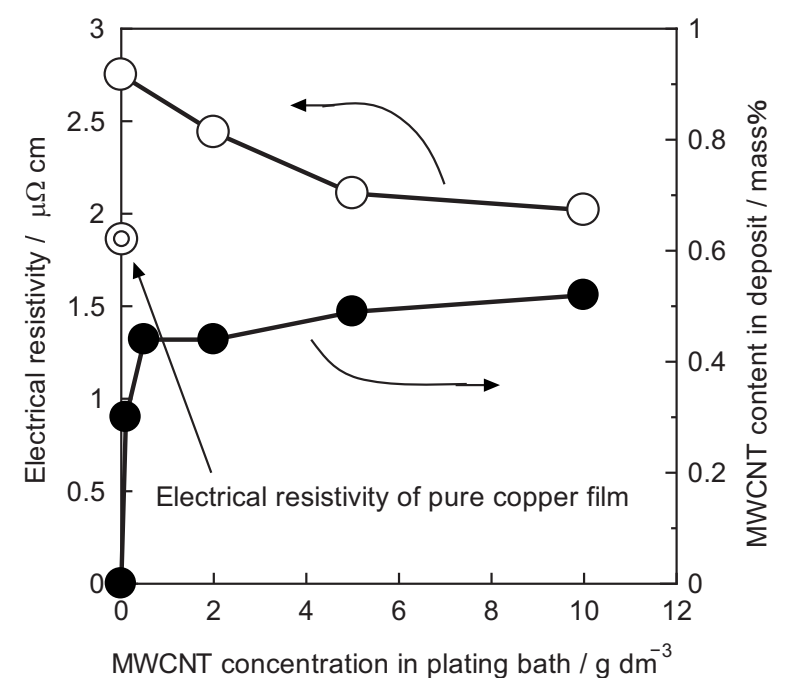

Figure 15. Relationship between MWCNT concentration in plating bath, electrical conductivity, and MWCNT content in film. Current density: $1 \mathrm{~A} \mathrm{dm}^{-2}$. Temperature: $25^{\circ} \mathrm{C}$. The double circle symbol indicates the electrical resistivity of the pure copper film electrodeposited from the base bath.

the electrical resistivity of an MWCNT used in the present study has been reported to be around $100 \mu \Omega \mathrm{cm}$, it is thought that the MWCNTs were not beneficial for the decrease in the electrical resistivity of the films.

Table I shows the measured thermal conductivity of the various films. The thermal conductivity of a pure copper film formed from the base bath was $392 \mathrm{~W} \mathrm{~m}^{-1} \mathrm{~K}^{-1}$, whereas that of the copper film formed from the composite plating bath without MWCNTs (base bath $+2 \times 10^{-5} \mathrm{~mol} \mathrm{dm}^{-3}$ PA-5000) was $353 \mathrm{~W} \mathrm{~m}^{-1} \mathrm{~K}^{-1}$, which is obviously lower than that of the pure copper film. Therefore, the thermal conductivity of the film was reduced by the incorporation of PA-5000 in the film. The thermal conductivity of the $\mathrm{Cu}-0.42$ mass \% MWCNT composite film was $355 \mathrm{~W} \mathrm{~m}^{-1} \mathrm{~K}^{-1}$, which is obviously lower than that of the pure copper film and almost the same as that of the copper film without MWCNTs. It is thought that the incorporated PA-5000 in the composite film decreased the thermal conductivity of the film compared with the pure copper film. Fujii et al. and Chang et al. reported that the thermal conductivity of individual MWCNTs decreased with increasing diameter. ${ }^{18,19}$ The thermal conductivity of individual MWCNTs used in the present study has been reported to be around $1200 \mathrm{~W} \mathrm{~m}^{-1} \mathrm{~K}^{-1}$ at room temperature. Kim et al. reported that the thermal conductivity of an individual MWCNT of $14 \mathrm{~nm}$ diameter was over $3000 \mathrm{~W} \mathrm{~m}^{-1} \mathrm{~K}^{-1}$, and the thermal conductivity of bundled MWCNTs rapidly decreased with increasing diameter of the bundled MWCNTs. ${ }^{20}$ Because the $\mathrm{Cu}-0.42$ mass \% MWCNT composite film contains individually well-dispersed MWCNTs (in other words, MWCNTs that are not bundled, as shown in Fig. 10f), it can be expected that the MWCNTs in the film show a thermal conductivity of an individual MWCNT. However, as the individual

Table I. Thermal conductivity of the different films.

\begin{tabular}{lc} 
Plating film & $\begin{array}{c}\text { Thermal conductivity } \\
\left(\mathrm{W} \mathrm{m}^{-1} \mathrm{~K}^{-1}\right)\end{array}$ \\
\hline Pure copper film & 392 \\
Copper film & 353 \\
Cu-0.42 mass \% CNT composite film & 355
\end{tabular}

thermal conductivity of the MWCNTs used in the present study is not very high and the MWCNT content is also not very high, and, moreover, considering that the thermal conductivity of copper is naturally very high, the effect of the presence of MWCNTs did not clearly emerge, resulting in the same thermal conductivity value as that of the copper film.

\section{Conclusions}

Using an electrodeposition technique with a sulfate bath, we have formed and studied $\mathrm{Cu}-\mathrm{MWCNT}$ composite films. The main conclusions of the investigation are as follows:

1. The surface morphology of the films was affected by the current density, and a relatively smooth surface was obtained at a lower current density.

2. The microstructure of the films was significantly affected by temperature, and a relatively compact microstructure was obtained at lower temperatures.

3. Composite films with homogeneously dispersed MWCNTs in the copper matrix without any voids and gaps between MWCNTs and the copper matrix could be fabricated.

4. The MWCNT content in the composite films increased with increasing MWCNT content in the plating bath, reaching a maximum of 0.55 mass $\%$.

5. The internal stresses in the films were tensile.

6. Hardness values of the composite films ranged from 100 to $150 \mathrm{HV}$.

7. The electrical conductivities of the composite films were in the range of $2-2.5 \mu \Omega \mathrm{cm}$.

8. The thermal conductivity of the $\mathrm{Cu}-0.42$ mass $\%$ MWCNT composite film was $355 \mathrm{~W} \mathrm{~m}^{-1} \mathrm{~K}^{-1}$.

\section{Acknowledgments}

This research was supported by the CLUSTER (second stage) of the Ministry of Education, Culture, Sports, Science and Technology, Japan. ticle.

Shinshu University assisted in meeting the publication costs of this ar-

\section{References}

1. A. Oberlin, M. Endo, and T. Koyama, J. Cryst. Growth, 32, 335 (1976).

2. S. Iijima, Nature (London), 354, 56 (1991).

3. X. H. Chen, J. C. Peng, X. Q. Li, F. M. Deng, J. X. Wang, and W. Z. Li, J. Mater Sci. Lett., 20, 2057 (2001).

4. X. H. Chen, C. S. Chen, H. N. Xiao, X. B. Liu, L. P. Zhou, S. L. Li, and G. Zhang, Tribol. Int., 39, 22 (2006).

5. L. Shi, C. F. Sun, P. Gao, F. Zhou, and W. M. Liu, Surf. Coat. Technol., 200, 4870 (2006).

6. X. H. Chen, C. S. Chen, H. N. Xiao, F. Q. Cheng, G. Zhang, and G. J. Yi, Surf. Coat. Technol., 191, 351 (2005).

7. S. Arai and M. Endo, Electrochem. Solid-State Lett., 7, C25 (2004).

8. S. Arai and M. Endo, Electrochem. Commun., 7, 19 (2005).

9. S. Arai, T. Saito, and M. Endo, Electrochem. Solid-State Lett., 11, D72 (2008).

10. S. Arai, M. Endo, T. Sato, and A. Koide, Electrochem. Solid-State Lett., 9, C131 (2006)

11. S. Arai, T. Saito, and M. Endo, J. Electrochem. Soc., 154, D530 (2007).

12. S. Arai, A. Fujimori, M. Murai, and M. Endo, Mater. Lett., 62, 3545 (2008).

13. S. Arai and M. Endo, Electrochem. Commun., 5, 797 (2003).

14. S. Arai, M. Endo, and N. Kaneko, Carbon, 42, 641 (2004).

15. M. Endo, CHEMTECH, 18, 568 (1988)

16. M. Endo, Y. A. Kim, T. Hayashi, Y. Fukai, K. Oshida, M. Terrones, T. Yanagisawa, S. Higaki, and M. S. Dresselhaus, Appl. Phys. Lett., 80, 1267 (2002).

17. M. Paunovic and M. Schlesinger, Fundamentals of Electrochemical Deposition, p. 74, John Wiley \& Sons, New York (1998).

18. M. Fujii, X. Zhang, H. Xie, H. Ago, K. Takahashi, T. Ikuta, H. Abe, and T. Shimizu, Phys. Rev. Lett., 95, 065502 (2005).

19. C. W. Chang, A. M. Fennimore, A. Afazasiev, D. Okawa, T. Ikuno, H. Garcia, D. Li, A. Majumdar, and A. Zettl, Phys. Rev. Lett., 97, 085901 (2006).

20. P. Kim, L. Shi, A. Majumdar, and P. L. McEuen, Phys. Rev. Lett., 87, 215502 (2001). 